\title{
Differencial Serum Proteomes between Subphenotypes of Nonsyndromic Cleft Lip with or without Cleft Palate Hong $\mathrm{He}^{1,2 \#}$, Mengyun Zhang ${ }^{1}$, Ying Wang ${ }^{1}$, Guoyun Wang ${ }^{3 \#}$, Feiyun Ping ${ }^{3^{*}}$, Xudong $\mathbf{M a}^{4^{*}}$
}

${ }^{1}$ The affiliated Stomatology Hospital, Zhejiang University School of Medicine, 395 Yan' an Rd, Hangzhou, China.

${ }^{2}$ Key Laboratory of Oral Biomedical Research of Zhejiang Province, Hangzhou China.

${ }^{3}$ The affiliated Second Hospital, Zhejiang University School of Medicine, 88 Yan'an Rd, Hangzhou, China.

${ }^{4}$ Huzhou University. 759, East 2nd Road, Huzhou, China.

honghehh@zju.edu.cn

*Co-corresponding Authors: Xudong Ma, Feiyun Ping. Email: rainbow050607@126.com.

${ }^{\#}$ Co-first Authors.

Abstract

Nonsyndromic cleft lip with or without cleft palate (nsCL/P)accounts for the majority of orofacial clefting in humans. New insights into the etiology of $n s C L / P$ are requiring diversified and complementary investigative technologies. Since proteins act as the functional end products of gene expression, this investigation examined some distinct protein expression profiles of genes related to $n s C L / P$ by analyzing differentially optimized peripheral serum protein mass spectrum peak values, utilizing Enhanced Laser Desorption Ionization Time of Flight (SELDI-TOF) technology. The differential peak values of protein 4119.1711 and 5639.1775 were discriminated repectively between cleft children and normal controls. 4079.4151, 5482.6131, 5684.2834, and 33310.9487 were cleft boys versus cleft girls. 2745.7079, 4473.4883, 6454.9339, 6560.7769, and 6654.3226 were cleft lip only versus cleft palate only. 4178.7872, 7842.6306, and 8147.0166 were cleft lip only versus cleft lip and palate. 4160.0878 and 5708.5676 were cleft lip only versus normal controls. These results indicate to be assistant for genomic etiology of nsCL/P.

Keywords: Proteomics; Genetics; SELDI-TOF-MS; Congenital abnormality; Nonsyndromic cleft lip with or without cleft palate (nsCL/P)

\section{INTRODUCTION}

Nonsyndromic cleft lip with or without cleft palate (nsCL/P) is one of the most common congenital deformities, with an incidence of $0.5-1.0 \%$ world widely and a male to female ratio as1.5-2.0 : 1.0. In contrast to the less common syndromic forms of $\mathrm{CL} / \mathrm{P}$, which are often due to single genes that cause maxillofacial defects accompanied with other systemic diseases or malformations, the major 50$70 \%$ of clefts are nonsyndromic which are generally acknowledged to be caused by multiple susceptibility genes as well as environmental factor ${ }^{1-6}$. Correlations have been found between MSX1, MYH9,WNT, PVRL3, TGF $\alpha$, RAR $\alpha$ BMP 4 TGF $\beta_{2}$, TGF $\beta_{3,}$ MSX BCL ${ }_{3}$, F13 $\alpha$ or IRF 6 and nsCL/P by scholars from gene territory ${ }^{2,5,7-}$ ${ }^{16}$. However, results can differ, due to the complexity of the etiology, the uncertainty of the inheritance patterns, the limitations of Genotyping studies, and differences among study samples ${ }^{17-19}$. With a new insight, the application of proteomics may increase our understanding of nsCL/P, since gene mutations are manifested via proteins, and hence there should be certain differentially expressed proteins that may be discovered. We applied the proteomic technique of Surface Enhanced Laser Desorption Ionization Time of Flight (SELDI-TOF) to cleft patients and normal human controls in this research, expecting to learn more etiology about nsCL/P.

\section{METHODS}

\section{Clinical Data}

Diagnoses were confirmed by excluding the syndromes known to us, including Van der Woude syndrome, Kabuki syndrome, Meckel syndrome. After consent 
Differencial Serum Proteomes between Subphenotypes of Nonsyndromic Cleft Lip with or without Cleft Palate

was granted and prior to any therapeutic intervention, fasting peripheral blood samples were obtained in the early morning from pediatric patients in the Oral and Maxillofacial Surgery Department of Second Affiliated Hospital, School of Medicine, Zhejiang University from March 2005 to January 2006. The experiments and control subjects were both comprised of 18 boys and 12 girls aged 0.3-6 years, respective30 subjects for experimental and control groups. Control groups were from healthy children outpatients for regular dental examinations. Sera were separated at once and stored at $-20{ }^{\circ} \mathrm{C}$ until use. The experimental group was divided into cleft lip only, cleft palate only, cleft lip and palate. No biological kinship existed among the subjects.

\section{Laboratory Procedures}

To use SELDI-TOF biotechnology we included serum, urine, secretions, cell lysate, and tissue sample proteins with energy absorbing molecules on the chip after removing impurities and other contaminators with buffer and drying. Following thawing and 5 minutes of centrifugation (3 $000 \mathrm{r} / \mathrm{min}$ ), $10 \mu \mathrm{l}$ sample was added to $90 \mu \mathrm{l} 0.5 \%$ U9 ( 9 mol/L urea, $0.15 \%$ CHAPS (3[(3-cholamidopropyl) dimethylammonio]-1-propan esulfonate) pH7.14, and incubated for $60 \mathrm{~min}$ at $4{ }^{\circ} \mathrm{C}$ in albumin affinity resin(CibacronBlue 3GA, Sigma) with $600 \mathrm{r} / \mathrm{min}$ vigorous shaking. After 5 minutes centrifugation at $2000 \mathrm{r} / \mathrm{min}, 50 \mu \mathrm{l}$ supernatant was diluted to $200 \mu \mathrm{l}$ with $20 \mathrm{mmol} / \mathrm{L}$ HEPES pH7.14, and was installed into a 96-well Bioprocessor (Ciphergen). Samples were incubated for $60 \mathrm{~min}$ at $4{ }^{\circ} \mathrm{C}$ with $600 \mathrm{r} /$ min vigorous shaking, and the serum discarded. The chip was washed 3 times for 5 min each with $200 \mu$ l of 20mmol/L HEPES pH7.14, and 2 times for $1 \mathrm{~min}$ each with deionized water, $0.15 \mu \mathrm{l}$ energy absorbing molecule CHCA (Ciphergen) was added after drying, and duplicated one time.

\section{Seldi-TOF Biotechnology}

Samples were desorpted and ionized by laser and then accelerated to fly out through a vacuum tube and captured by the ion detecting receiver. Ciphergen SELDI Protein Biology System II plus (PBS II plus) and ProteinChip Software (Version 3.0, Ciphergen Biosystems) were used to read the chips and analyze the data. The square of the ion flight time is in inverse proportion to the ratio of molecule size and molecular charge. When the numbers of usually single charge in the tube ${ }^{20,21}$ are equal, the time of flight differs with the molecule size. The smaller the molecule is, the shorter the flight time would be; hence small molecules are first to reach the receiver. As reflected in a mass spectrum diagram, the peak position corresponds to molecular weight of the relevant protein compositions, and the spectral peak height corresponds to the number of the relevant protein compositions. Therefore, proteins can be identified by peak position and height. Differential proteins can be discriminated by comparison to the high-throughput spectrums between groups.

Laser intensity 135, 65 laser shots per sample, detector sensitivity 7, and automatically-detected peaks from 2000 to $30000 \mathrm{~m} / \mathrm{z}$ were used. Mass accuracy was calibrated to less than $0.1 \%$ using the All-in- 1 peptide molecular mass standard (Ciphergen Biosystems). The peaks were normalized and simultaneously existed in more than $10 \%$ of samples with a bias lower than $0.3 \%$ for the same protein $\mathrm{m} / \mathrm{z}$ peak in different samples. Noises were filtrated (first signal to noise ratio $>2.2$, second valued as 1 ). Multivariate analysis of variance Kruskal-Wallis was used to compare the data of different groups and discrepant mass peaks groups were found and established.

\section{RESUlTS}

The statistically significant protein peak values of mass to charge ratio are illustrated in Table 1. Correlation comparisons between the differential protein peaks and the pathway proteins for such cell factors as TGFa, TGF $\beta_{2}, \operatorname{TGF}_{3}$, MSX BCL, F13 $\alpha$ MYH9, WNT, PVRL3, TGF $\alpha$, RAR $\alpha$ BMP4 and IRF6 were conducted through http://us.expasy.org/. The differential peak values of protein 4119.1711 and 5639.1775 were discriminated respectively between cleft children and normal controls (table 1). 4079.4151, 5482.6131, 5684.2834, and 33310.9487 were cleft boys versus cleft girls. $2745.7079,4473.4883,6454.9339,6560.7769$, and 6654.3226 were cleft lip only versus cleft palate only. 4178.7872, 7842.6306, and 8147.0166 were cleft lip only versus cleft lip and palate. 4160.0878 and 5708.5676 were cleft lip only versus normal controls 
Differencial Serum Proteomes between Subphenotypes of Nonsyndromic Cleft Lip with or without Cleft Palate

Table 1. Differential protein peak values.

\begin{tabular}{|l|l|}
\hline \multicolumn{1}{|c|}{ Group } & \multicolumn{1}{|c|}{ Differential protein peak values $(\mathbf{p}<\mathbf{0 . 0 1})$} \\
\hline Cleft children versus Normal controls & $4119.1711,5639.1775$ \\
\hline Cleft boys versus Cleft girls & $4079.4151,5482.6131,5684.2834,33309.9487$ \\
\hline Cleft lip only versus Cleft palate only & $2745.7079,4473.4883,6454.9339,6560.7769,6654.3226$ \\
\hline Cleft lip only versus Cleft lip and palate & $4178.7872,7842.6306,8147.0166$ \\
\hline Cleft lip only versus Normal controls & $4160.0878,5708.5676$ \\
\hline
\end{tabular}

\section{Discussion}

To date, similar with SCL/P, studies for nsCL/P also concentrated on single gene etiology. In fact, multiple genes defect and other factors account for nsCL/P. Although researches have demonstrated that any deficit or variation of one single gene involving embryonic fusion such as Epidermis Growth Factor (EGF) or MYH9, WNT, PVRL3, TGF $\alpha$, RAR $\alpha$ BMP4 could exacerbate initiation events and lead to the occurrence of a cleft, it is indispensable to study some feature proteins characteristically correlated to the formation of clefts. If they diminish the clinical expression of cleft or revise it to normal via reconstruction of the executive function of key proteins, guidance for treatment and intervention for the formations of cleft lip and palate would be achieved, considering that the morphological defect could be due to mutual effects among multiple cells under the control of numerous structural and regulatory proteins, as well as mutual action between cytological differentiation and migration of neural crest cells.

Furthermore, due to the high throughput of data and the comparison of tremendous protein molecules and multipeptide sequences, to understand the ontogeny and embryology of the disease from gene to protein and cell function and through to clinical manifestation, is far beyond the single capability of 2-dimentional electrophoresis, while, Surface Enhanced Laser Desorption Ionization Time of Flight (SELDI-TOF), on the other hand, affords greater technical capacity for functional proteomic research.

With regard to the etiology of $\mathrm{nsCL} / \mathrm{P}$, although genetic reports have inferred several candidate genes 2,7-14, there are seldom insights into the functionally dynamic steps in the pathology-from gene to protein to cell function and through to clinical manifestationhow transcription and translation are altered and how the altered proteins execute their functions. Since pathologicalstudy has suggested that theappearance of nsCL/P is evoked through a series of mutually affected protein receptors, it has become a novel starting point to research the functionally executive proteins for disease. Within this investigation, diversification of hormones and protein volume related to adolescence was avoided by limiting subject ages to less than 6 years old, as was also done on the familial patients to exclude the intervention of any familial inherited genes. The appearance of differential protein peak values 4119 and 5639, which were discriminated between cleft pediatric patients and normal controls (table 1), respectively, infers the existence of differential functional proteins. Even though they could not be judged to be genetically correlated receptor proteins, this research still, reveals the existence of differential proteins or multipeptides between cleft and normal subjects.

Secondly, this study provides additional verification that the mechanisms of cleft lip with or without palate (nsCLP) are different from single cleft palate (CP), and single cleft lip with single cleft palate. The bigger quantity of differential proteins as 3-5 differentially distinguished peaks in respective cleft groups (table 1) suggests that the protein pathways for mechanisms of pure cleft lip or palate or cleft lip with palate are discrepant. This concurs with many scholars' views 1,17,18, based on embryologic and epidemiologic evidence, that the primary and secondary palate are separately formed. Furthermore, the simultaneous existence of nsCL/P and purely cleft palate in the same family is very rarely found, supporting the distinction between affected genes. In contrast, some current quantitative genetics researchers argue that a few factors leading to $\mathrm{nsCL} / \mathrm{P}$ are also pathological for $\mathrm{CP}{ }^{22}$.

Thirdly, the establishment of clinical phenotypes according to the severity of the cleft is confirmed. From the results of this research, the observation of differential proteins illustrates that, even for pathologically visible clefts, there exist different degrees of protein/receptor regulation that impact the severity and phenotype of the cleft. The differential 
Differencial Serum Proteomes between Subphenotypes of Nonsyndromic Cleft Lip with or without Cleft Palate

proteins, evidently structural and regulatory proteins, comprise the pathways leading to the fusion of facial or palate protrusions and signal cellular differentiation and interaction as well as neural crest migration, eventually and directly bringing about the clinical manifestations.

Within the limitations of this current work, we include small sample size and the distance to genetics, genecology, and epidemiology. When comparing the mass/charge of the differential proteins with the database at http://us.expasy.org/, the dispersion of the differential proteins was found to be limited, concentrated on certain PI values, which have not yet been reported to have any relationship with the incidence of cleft lip or palate, despite the exclusion of hormone and familial proteins. Larger samples such as enrollment of adolescents and familial subjects should strengthen the results. The research results should not be inferred to be the actual source of dysmorphism ${ }^{15}$. This research also depends on the temporary limitations of the genes included for study and Subsequent study would include genes such as MTHFR and BCL3, which may have weaker effects on clefting.

\section{ACKNOWLEDGEMENT}

The authors sincerely express their grateful appreciation to Dr. Katherine Neiswanger from the School of Dental Medicine at the University of Pittsburgh for her kind help in English revision.

The work was supported by the Teaching Reform Project of Zhejiang University School of Medicine yxyb20172030. National and provincial Health Commission Co-construction Fund WKJ-ZJ-1623. National Health Commission Public Welfare Fund(201502018). National Key R\&D Program of China 2016YFC0902702. Fund 2008C33026 [2011]666 from Science and technology Office of Zhejiang Province. 2016 Fund for 151 talents second level Zhejiang Province 2014-2017. Scientific Research Foundation for the Returned Oversea Chinese Scholar J20120036 from HR Office of Zhejiang Province. Baoshi Oversea Scholarship zups1507 2013-2015. China Scholarship Council [2009]3004 and Research Program 2013KYB247 from Zhejiang Hygiene Bureau.

\section{REFERENCES}

[1] Blanton SH, Burt A, Stal S. Family-based Study Shows Heterogeneity of a Susceptibility Locus on Chromosome 8q24 for Nonsyndromic Cleft Lip and Palate. Birth Defects Res PartA-Clini Mol Teratology. 2010; 88: 256-259.

[2] Tasanarong P, Pabalan N, Tharabenjasin P, Jarjanazi H. MSX1 gene polymorphisms and non-syndromic cleft lip with or without palate (NSCL/P): A meta-analysis. Oral Dis, 2019, 25(6):1492-1501.

[3] Jianyan L, Zeqiang G, Yongjuan C, et al. Analysis of interactions between genetic variants of BMP4 and environmental factors with nonsyndromic cleft lip with or without cleft palate susceptibility. [J]. Int J Oral Maxillofac Surg, 2010, 39(1):0-56.

[4] Liu DL, Wang MY, Yuan Y, Schwender H, Wang H, Wang P, et al. Gene-gene interaction among cell adhesion genes and risk of nonsyndromic cleft lip with or without cleft palate in Chinese case-parent trios. Mol Geneti Genomi Med,2019,7(10):872.

[5] AiniwaerMijiti, Wang L, Guli, AdiliMoming, Association of single-nucleotide polymorphisms in the IRF6 gene with non-syndromic cleft lip with or without cleft palate in the Xinjiang Uyghur population[J]. British Journal of Oral and Maxillofacial Surgery, 2015, 53(3):268-274.

[6] Imani MM, Mozaffari HR, Sharifi R, Sadeghi M. Polymorphism of reduced folate carrier 1 (A80G) and non-syndromic cleft lip/palate: A systematic review and meta-analysis.[J]. Archives of oral biology,2018,98:273-279.

[7] Kanno K, Suzuki Y, Yamada A, et al. Association between nonsyndromic cleft lip with or without cleft palate and the glutamic acid decarboxylase 67 gene in the Japanese population. [J]. American J Med Genetics Part A. 2004; 127A: 11-16.

[8] Zhu J H, Ren A G, Hao L, et al. Study on the association between transforming growth factor $\alpha$ gene Taq I variant and cleft lip with or without cleft palate. [J]. Chinese Journal of Epidemiology, 2006,27(3):245-8.

[9] Chiquet B T, Blanton S H, Burt A, et al. Variation in WNT genes is associated with non-syndromic 
Differencial Serum Proteomes between Subphenotypes of Nonsyndromic Cleft Lip with or without Cleft Palate

cleft lip with or without cleft palate.[J]. Human Molecular Genetics, 2008, 17(14):2212-2218.

[10] Chiquet B T, Hashmi S S, Henry R, et al. Genomic screening identifies novel linkages and provides further evidence for a role of MYH9 in nonsyndromic cleft lip and palate.[J]. European Journal of Human Genetics, 2008, 17(2):195204.

[11] Diercks G R, Karnezis T T, Kent D T, et al. The Association Between Interferon Regulatory Factor 6 (IRF6) and Nonsyndromic Cleft Lip With or Without Cleft Palate in a Honduran Population. [J]. The Laryngoscope, 2009, 119(9):1759-1764.

[12] Sozen MA, Hecht JT. Mutation and association analysis of the PVR and PVRL2 genes in patients with non-syndromic cleft lip and palate.[J]. Genetics and Molecular Biology, 2009, 32(3):466469.

[13] Suazo JS, Santos JLM, Silva VA. Possible association due to linkage disequilibrium of TGF $\alpha, \operatorname{RAR} \alpha$ and BCL3 with nonsyndromic cleft lip with or without cleft palate in the Chilean population. [J].Revista Medica de Chile. 2005; 133: 1051-1058.

[14] Suazo, José, Santos, José Luis, Jara L, et al. Association Between BoneMorphogeneticProtein 4 Gene Polymorphisms with Nonsyndromic Cleft Lip with or without Cleft Palate in a Chilean Population.[J]. DNA and Cell Biology, 2010, 29(2): 59-64.

[15] Nishikori M. High-level expression of BCL3 differentiates $\mathrm{t}(2 ; 5)(\mathrm{p} 23 ; \mathrm{q} 35)$-positive anaplastic large cell lymphoma from Hodgkin disease. [J]. Blood, 2003, 101(7):2789-2796.
[16] Blanton S H, Cortez A, Stal S, et al. Variation in IRF6 contributes to nonsyndromic cleft lip and palate.[J]. American Journal of Medical Genetics Part A, 2005, 137A(3):259-262.

[17] Blanton S . No evidence supporting MTHFR as a risk factor in the development of familial NSCLP. [J]. Am J Med Genet. 2000, 92(5):370-1.

[18] Kanno K, Suzuki Y, Yang X, et al. Lack of evidence for a significant association between nonsyndromic cleft lip with or without cleft palate and the retinoic acid receptor alpha gene in the Japanese population.[J]. Journal of Human Genetics, 2002, 47(6):269-274.

[19] Triin Jagomägi, Nikopensius T, Krjutskov K, et al. MTHFR and MSX1 contribute to the risk of nonsyndromic cleft lip/palate.[J]. European Journal Of Oral Sciences, 2010, 118(3):213-220.

[20] Schipper R, Loof A, Groot J D, et al. SELDI-TOFMS of saliva: Methodology and pre-treatment effects.[J]. Journal of Chromatography B, 2007, 847(1):45-53.

[21] Gallo C, Ciavarella D, Santarelli A, et al. Potential Salivary Proteomic Markers of Oral Squamous Cell Carcinoma.[J]. Cancer Genomics \& Proteomics, 2016, 13(1):55.

[22] Scapoli L, Martinelli M, Arlotti M, et al. Genes causing clefting syndromes as candidates for nonsyndromic cleft lip with or without cleft palate: a family-based association study.[J]. European Journal of Oral Sciences, 2008, 116(6):507-511.

Citation: Hong He” ${ }^{\#}$, Mengyun Zhang, Ying Wang, Guoyun Wang", Feiyun Ping*, Xudong Ma*. Differencial Serum Proteomes between Subphenotypes of Nonsyndromic Cleft Lip with or without Cleft Palate. Archives of Dentistry and Oral Health. 2019; 2(2): 24-28.

Copyright: (c) 2019 Hong He, Mengyun Zhang, Ying Wang, Guoyun Wang, Feiyun Ping, Xudong Ma. This is an open access article distributed under the Creative Commons Attribution License, which permits unrestricted use, distribution, and reproduction in any medium, provided the original work is properly cited. 